\title{
Technoperformances: using metaphors from the performance arts for a postphenomenology and posthermeneutics of technology use
}

\author{
Mark Coeckelbergh $^{1}$
}

Received: 18 June 2019 / Accepted: 28 November 2019 / Published online: 31 December 2019

(c) The Author(s) 2019

\begin{abstract}
Postphenomenology and posthermeneutics as initiated by Ihde have made important contributions to conceptualizing understanding human-technology relations. However, their focus on individual perception, artifacts, and static embodiment has its limitations when it comes to understanding the embodied use of technology as (1) involving bodily movement, (2) social, and (3) taking place within, and configuring, a temporal horizon. To account for these dimensions of experience, action, and existence with technology, this paper proposes to use a conceptual framework based on performance metaphors. Drawing on metaphors from three performance arts—-dance, theatre, and music — and giving examples from social media and other technologies, it is shown that we can helpfully describe technology use and experience as performance involving movement, sociality, and temporality. Moreover, it is argued that these metaphors can also be used to reformulate the idea that in such uses and experiences, now understood as "technoperformances", technology is not merely a tool but also takes on a stronger, often non-intended role: not so much as "mediator" but as choreographer, director, and conductor of what we experience and do. Performance metaphors thus allow us to recast the phenomenology and hermeneutics of technology use as moving, social, and temporal —indeed historical—affair in which technologies take on the role of organizer and structurer of our performances, and in which humans are not necessarily the ones who are fully in control of the meanings, experiences, and actions that emerge from our engagement with the world, with technology, and with each other. This promises to give us a more comprehensive view of what it means to live with technology and how our lives are increasingly organized by technology - especially by smart technologies. Finally, it is argued that this has normative implications for an ethics and politics of technology, now understood as an ethics and politics of technoperformances.
\end{abstract}

Keywords Technoperformance $\cdot$ Postphenomenology $\cdot$ Posthermeneutics $\cdot$ Performance $\cdot$ Movement $\cdot$ Sociality $\cdot$ Temporality $\cdot$ Metaphor $\cdot$ Technology $\cdot$ Philosophy of technology $\cdot$ Dance $\cdot$ Theatre $\cdot$ Music

\section{Introduction: gaps in postphenomenology and posthermeneutics}

Postphenomenology and posthermeneutics as initiated by Don Ihde (e.g., Ihde 1990, 1993, 1999) and later developed by scholars such as Peter-Paul Verbeek and Robert Rosenberger are part of the empirical turn in philosophy of technology, which shifted from Heideggerian analysis of technology to empirical analysis of concrete technologies. Postphenomenology still links to the phenomenological tradition with its interest in experience and embodiment

Mark Coeckelbergh

mark.coeckelbergh@univie.ac.at

1 Department of Philosophy, Universitätsstraße 7 (NIG), 1010 Vienna, Austria
(Husserl, Heidegger, Merleau-Ponty), but focuses on our practical dealings with material technologies. Taking distance from postmodern semiotics, Ihde also proposed an expanded, material hermeneutics that does not focus on texts but on material artifacts and visual perception. And in contrast to Heidegger, he also borrowed the pragmatist attention to use of technologies rather than seeing technology in ontological and transcendental terms.

Like most philosophy of technology after the empirical turn, these directions of research have been very focused on artifacts and what they do, that is, on the mediating role of artifacts in human-world and human-technology relations (Verbeek 2005); the human user has received much less attention. Embodiment has been emphasized by Ihde (e.g., Ihde 2002), but usually embodiment has been understood in a rather static way and the focus has been on individual 
perception, on embodiment in relation to such perception, and on how artifacts are embodied. When in a rare case (in his comments on Pickering and Haraway in Bodies in Technology) Ihde picks up the dance metaphor (Ihde 2002, 88-100), he does so in order to discuss symmetries and asymmetries between humans and nonhumans. Like in Pickering (1995), the metaphor is employed at a very abstract level, and is not used to conceptualize what happens in terms of the moving body when we use concrete technologies. To take up one of Ihde's own examples: when we write with a pen or type, this indeed involves bodily actions and motions (Ihde 2002, 96-97); but this needs to be analyzed.

Other postphenomenology scholars tend to inherit one or more of these directions and biases. For example, Van den Eede (2005) discusses self-tracking technologies using Ihde's human-world relations scheme: the technologies construct and change our ways of seeing (including how we see ourselves and our body) and shape our behavior. But the moving body remains out of sight. Wellner seems to do better when she writes about the mobility of the cell phone and discusses new experiences of mobility (Wellner 2016). Influenced New Mobility Studies and by Deleuze and Guattari, she proposes the concept 'becoming-mobile'. But for her this is about moving from real to virtual and augmented spaces, not necessarily encompassing physical movement (Wellner 2016, 151), and about the user's relation to the world-involving Ihde's embodiment, hermeneutic, and alterity relations (152). In other words, the user is still mainly conceptualized as a perceiver who "moves" mainly in a rather abstract sense (between worlds) and the embodied relation is about what the artifact does. Another example: Rosenberger (2017) has analyzed how the design of artifacts in public spaces can have political purposes and consequences, in particular, how specific designs of benches are meant to exclude the homeless. This helps a lot to bring in a more social and political dimension. But the focus remains on the material artifacts; the human user is rather abstract; her movements, experiences, and (hi)stories remain in the background. His analysis in terms of Ihde's notion of multistabilty also makes it seem as if what is going on is only a matter of momentaneous mediations; like in Ihde and Verbeek, there is too little attention for the structuring and prestructuring of experience and action, shaped by artifacts and by humans, and taking place at various moments in time.

More generally, what is largely missing is an integrated account that, while acknowledging the role of material artifacts and their design, also makes sense of the human user and experiencer as (1) being embodied in the sense of having and being a moving body, (2) a social being, and (3) a being situated and existing in a temporal horizon. Moreover, it is unclear how postphenomenology and mediation theory can do full justice to the ways how technologies structure and pre-structure our experience and actions.
In order to remedy these lacunas and to complement recent work that already points to mobility and sociality, I propose to use metaphors from the performing arts. This paper argues that we can use metaphors from dance, theatre and music in order to describe and interpret technology use and experience as performance involving movement, sociality, and temporality. More attention is given to the human user of technology, who is recast as a performer. Moreover, it is shown that one can also use these metaphors to re-describe the unintended consequences of technology: not in terms of "mediation" but in terms of choreography, directing, and conducting. This brings out the role of technology as organinzing and (pre-)structuring our performances and experiences (rather than "mediating") and expresses that we are not fully in control of the meanings, experiences, and actions that emerge from our engagement with technology, with others, and with the world. As such, it can be considered as a contribution to a revision of postphenomenology and posthermeneutics and, more generally, a significant move toward thinking about technology from a performative point of view with an emphasis on movement, sociality, and temporality. One could also say that attention to what I call "technoperformances" helps to historicize technology use(rs) and experience. And by paying attention to metaphor, I continue my project to investigate links between language and technology.

Note that in this paper I restrict the metaphors to the fields of dance, theatre, and music, but there are of course more performative practices can be mined for metaphors to assist and further develop thinking about humans and technology, for example, stage magic and even philosophy itself. Here I restrict myself to these three domains for the purpose of making an effective argument and presentation (indeed performance) within the space of a journal article.

Note also that this intervention by no means denies the materiality of technology and the importance of analyzing specific and concrete material technologies. It is not opposed to the empirical turn and does not seek to undo the benefits of postphenomenology and posthermeneutics. It "merely" wants to bring in the dimensions of movement, sociality, and temporality and the structural role of technology in a framework for phenomenological and hermeneutical analysis that risks painting an impoverished view of what it means to use technology and what kind of knowledge and experience are involved when we use technology. And while not hostile to the study of language at all (metaphor is central here), the proposed approach also sides with postphenomenology and contemporary STS in their rejection of postmodern approaches obsessed with signs and with text metaphors. In performance ecologies (see below), text/writing is only one kind of technology that can be used and it is not even necessary, for example, in improvisation without script or when working with different media. Finally, the use of the 
performance metaphor also continues Ihde's tradition of anti-dualism - although I will not further develop this point here.

The structure of the paper is threefold. It first follows the three metaphors dance, theatre, and music. In each case, technology use and experience are re-described using performance metaphors: moving with technology, acting with technology, and playing with technology. For this purpose, theories about these performance fields are used (e.g., philosophy of dance and dance theory) and also theories in the social sciences that use or engage with these metaphors (e.g., Latour's theatre metaphors). I focus on the aspects of movement, sociality, and temporality. While performances in dance, theatre, and music have all three aspects, for the purpose of this paper, movement is discussed by means of the metaphor of dance, sociality by means of the metaphor of theatre, and temporality by means of the metaphor of music. I also pay some attention to improvisation. Then it is argued that technology is not only a tool or "co-actor" (actant) but also choreographs, directs, and conducts us; it also organizes our movements, directs how we play our roles, and configures our temporal doings. Finally, it is shown that this has normative implications, which need to be discussed in the framework of an ethics and politics of technology understood as an ethics and politics of technoperformances.

I will focus on smart digital technologies and offer examples such as use of smartphones and social media since these technologies seem to especially take on a choreographing, directing, and conducting role, but I will also refer to hammers, electric guitars, cars, pens, keys, etc., to show how the proposed approach works for all kinds of technologies. Of course more work needs to be done; I hope that this conceptual framework may inspire others to analyze a whole range of technologies in terms of performance metaphors.

\section{Movement, sociality, and temporality: towards a more comprehensive and performance-oriented (post) phenomenology and (post)hermeneutics of technology}

\subsection{Movement: using metaphors from dance}

Human beings as technology users and experiencers are not only embodied or have embodiment relations with some of their artifacts, as Ihde has argued; they also have and are moving bodies. We move in general and we move as we use technology and with technology. We are moving, kinetic beings, in general and when we use technologies. To articulate this, we can use a metaphor from the performing arts, which is all about movement and moving bodies: dance.
Dance of course involves bodies and embodiment. This embodiment gives rise to knowledge and experiencein dance and everywhere. Merleau-Ponty, one of Ihde's favorite philosophers, already argued that we perceive the world through our bodies (Merleau-Ponty 2005, 239). Dance theorists such as Kozel (2007) and Klemola (1991) have followed Merleau-Ponty in stressing the role of the lived body in dance knowledge and dance experience. Embodiment is thus not only a particular human-technology relation; it is something existential and it makes possible knowledge and experience. But dance is not only about embodiment; it is also movement. If we have and are bodies, then these are moving bodies. Movement plays an important role in cognition. Merleau-Ponty suggested that we think through movement. The moving body understands without representation (Merleau-Ponty 2005, 162). And dance is also a matter of movement. In her classic The Phenomenology of Dance (Sheets-Johnstone 2015), Maxine Sheets-Johnstone famously defines dance as movement. The lived experience of dance is an experience of movement. To dance is to move and to be moved. To be moved means that the dancer controls her body, but also feels that something is happening. Kozel writes: 'the dance dances through the dancer' (Kozel 2007, 39). The expert dancer has acquired implicit knowledge and skill. There is control but there is also flow and letting things happen. Furthermore, dance happens in time and space. Sheets-Johnstone even suggests that phenomenologically speaking it creates its own time and space (1966, 43). It is temporal in the sense that it happens in time but also configures time. Dance also has a rhythm. And dance is more than movement; it is also a social activity. There is interaction with others on the stage and resonance with the audience. Dance is not just movement but also movement with others and before others. It also takes places in a cultural context. Foster (2011) has argued that dance is socially constructed. Finally, in Western contemporary dance, the movements and interactions of the dancers are organized and directed by a choreographer. Sometimes the dancers themselves are co-choreographer. And there is also improvised dance, for example, contact improvisation. For my purposes, I will use both metaphors: dance as choreographed movement and dance improvisation.

These insights from the phenomenology of dance and movement can now be used for theorizing the use and experience of technology. Our experience and existence as human beings is an embodied one-as Ihde would acknowledge-but it is also kinetic. Having and being a lived body involves movement. This movement makes possible knowledge and experience. When we use technology, the meaning of that use and indeed the use itself is shaped by and constituted by movement. Use of technology is a kinetic affair. If I use a hammer, this requires and involves movement. The same is true for the use of a computer and word processing 
program. The use of so-called digital technologies relies on, and is made possible by, the moving body. For example, if I use social media, for example, on a smartphone or a computer, then I have to move my body to take the phone, perform clicks, type, and so on. These movements may not be directly visible to the other and the user is usually not aware of them - this may well be one reason why social media use is sometimes misleadingly seen as less embodied, less social, abstracting, or taking place in a separate "online" or "virtual" environment-but they are bodily movements nevertheless. In this sense, we always dance with technology-even if we are not on a stage or in the theatre. Using a hammer, a word processing program, or a social media app means performing a kind of techno-dances or technoperformances: performances with and through technology. We move and dance with technology. We literally move our body to type, to move the cursor on the screen, and to perform clicks in a particular order, and we also move our eyes and we move through different pages and different online environments.

In order to do that, we have to learn a skill which gives us implicit knowledge. Think also about Merleau-Ponty's examples of the woman with the feather in the hat who moves through an opening without measuring or the blind man's stick: they have implicit knowledge. Dancing with technology is a matter of control-I use and experience the technology as a tool and I am in control of the tool-but there is also a sense in which the movement with the technology is something that happens to me. When I use my phone to message someone or when I write this text, I do not have to think about the gesture of picking up the phone or about the movement of my fingers and hands on the keyboard or on the screen. The knowledge needed for the dance of my fingers and hands is incorporated, as Merleau-Ponty already said about typewriting $(2005,167)$ and playing an organ. It is an embodied know-how. I think and act through the technology, through the body, and through the movement. The dance of typewriting dances through me as much as I control "my" writing dance.

Furthermore, dance also "happens" and is "out of control" in the sense that it is not always (fully) choreographed and can be more or less a matter of improvisation. For technology, this means that our use of technology is not always fully intended and pre-scripted and choreographed. Use can be improvised, in the sense of not intended by the designer or not choreographed by those who want the user to move in certain ways. Particular uses can be unforeseen by all parties involved-including the user. For example, to use one of Ihde's examples again: in a specific situation, a pen can suddenly become a weapon. This then involves very different (sequences of) movements. And let us change the metaphor: a particular technology should not only be analyzed in terms of a different way of seeing, as Ihde does by relying on variational analysis and using the concept of multistability, but also in terms of a different way of moving and indeed a different dance.

Moreover, like dance, moving with technology is social and takes place in a temporal setting. As we move with technology, we perform before others, we respond to others, and we configure a social and temporal setting. Even if our micro-movements may not always be visible to the other, use of technologies such as social media is a dance before others and often with others, moves others, and has always a temporal dimension. When we use social media, we not only interact with a screen, a phone, or an app, we also interact with others through the technology. In this social dance, we play different roles. Let me further develop the social aspect of technoperformances using metaphors from theatre and music. I will also further elaborate the idea that technology takes more control and is more than a tool using the choreography metaphor. This will also take us beyond the literal meaning of (bodily) movement and dance.

\subsection{Sociality: using metaphors from theatre}

Some theatre metaphors have already been used for thinking about technology. Most prominently, Akrich and Latour, influenced by Greimas's semiotics, argued that things can be actants (Akrich and Latour 1992; Latour 1993): a kind of non-human actors that also do things, for example, in science help to construct knowledge. And material artifacts can have a "script", telling users not only how to use the artifact but sometimes also telling users what to do (prescribe). They give the example of heavy keys, which have the script "give back the keys to the hotel" and which are actants in the sense that they do things. However, Akrich and Latour did not further and systematically reflect on their use of theatre metaphors and on what a more general performance-oriented conceptual framework could mean for thinking about technology. And like in current postphenomenology, the stress is on what things do (see also Verbeek again) rather than what humans do with technology. I propose to remedy this by focusing more on the user and by starting from the work of Goffman. This can also help to give a more social twist to postphenomenology.

In The Presentation of Self in Everyday Life (1956), Goffman used theatre metaphors to describe the social life. When we appear before others, we perform in the sense that we control the impression we make on others. Presenting ourselves to others is a 'dramaturgical problem' (8). Performance occurs 'everywhere in social life' (8) and the social life can be described in terms of performance. We enact our personae on a daily basis (see also Schechner 1988, x). We play different roles in different settings (e.g.,work stage versus private stage), and we also often perform with others, for example, in teams at work. There are frontstages such as 
work environments versus backstages where we can relax (e.g., at home) and there are others who try to influence our performance (direct us). In feminist theory, Butler (1988) also famously claimed that our social identity, including gender identity, is performed. Gender is an act. Again the underlying idea is that as social beings we are performing beings. What we are is also at least partly what we are in the eyes of others; through our performances, we thus construct our identity. More generally, performance raises philosophical questions concerning personal identity. For example, are we merely the persona (mask) that we perform, or is there are a kind of "core identity" or identity "hidden" "behind" our performances, roles, and theatre masks? If the latter, how stable is that identity, and what is the precise relation between, on the one hand, what and who we are and, on the other hand, our performances? Finally, one should add that these performances always take place within a wider social and cultural context. There are already scripts, there is a tradition. For example, there are roles for men and women that are given in a particular social and cultural context; we may improvise, play, resist, try to change, etc., but there is already a performative tradition to which we have to respond. One could also say: there is already a history, which is a narrative history but also and always a history of performances, including ways of doing, ways of speaking, and ways of moving - and associated know-how.

These ideas can now be used to conceptualize use and experience of technology as social, something which postphenomenology has insufficiently done so far. Users of technology must be seen as social beings who act and perform with and through technology, perform before others, thereby rely on, interpret, and respond to pre-given roles and histories and also perform who and what they are, and in this way constitute themselves as subjects, selves, personae, and identities. For example, using social media technologies, users play roles and perform before others-even if usually they cannot see their audience (they can only guess since they cannot predict precisely who will see their posts). They appear to others on Facebook, for example, and try to control the impression they make to others. They perform their identity via the technology. The technology provides not just a technical platform but also a social stage. Perhaps users perform differently on different stages. But social media are one of the front stages on which they perform; when the smartphone is not used, the users are backstage. The same can be said of games when they provide possibilities for role play and, sometimes, experimentation with identities.

Using this metaphor also enables us to ask more questions about the relation between technology and identity, or about how to deal with histories. For example, following Butler we could say that users of these social media and games do not so much "express" an identity but rather constitute that identity by performing it. It is not the case that there are readymade identities offline waiting to be expressed online. At least part of the user's identity is made by performing online. In this sense, the online/offline distinction becomes a lot less relevant, at least when it comes to identity. What used to be called "online" is one of the stages on which we perform our social roles and identities. It is not a separate "technological" sphere but is part of the social life. Technology builds the stages of the social life and more and helps to actively shape the roles and identities. Digital technologies have a pervasive influence now and it becomes increasingly difficult to maintain that they constitute a separate performative sphere. For example, today it would be inaccurate and sound rather artificial to say that as an academic I have an "online" identity and an "offline" identity that are completely different and separate; both are entangled. It may be interesting to then inquire into the precise relation between online performance and what happens offline. And there may be different kinds of online performances and different performative spaces. But in any case, even offline we act and perform with technology. Users are not a-social beings, as often projected by classic postphenomenology; also when they use technology, they are social actors and social performers. They present themselves to others and respond to others.

These performances do not stand alone but take place within a wider social and cultural context (or one should say in order to get rid of the dominant text metaphor: conperformance) and performance history. There are already ways of performing online and offline in a particular social and cultural context or community that will shape my social media use. For example, if I write other academics on Facebook, there is already unwritten, implicit know-how to do that, which depends on patterns in past performances within the particular community (academia or a community within academia). Moreover, this social dimension does not exclude embodiment or movement; on the contrary, both toolkits of metaphors should be combined to emphasize that moving and dancing with technology are a social affair, and vice versa that our acting and performing on the social stage with technology is always also involving bodily movement. It is always embodied and has a kinetic dimension. To actonline or offline-is not only and not even necessarily to speak words; but everything one does is embodied and to act is always also to move.

\subsection{Temporality: using metaphors from music}

Technoperformances, so far described using dance and theatre metaphors, also have a temporal character. They take place in time and relate to time in various ways, and this gives their phenomenology and hermeneutic characteristics that have not been described yet by the more or less static vocabulary offered by the current postphenomenological 
framework. To describe the temporal characteristics of technology use and experience, I propose to use metaphors borrowed from music, understood here as performance rather than, say, as "works" or other objects such as "artifacts". There are of course all kinds of positions in the metaphysics of music; I side with Godlovitch (1998) who also takes distance from the Platonic idea that performance is a mere instantiation of "the work" and takes seriously music as performance.

Like dance and theatre, music as performance is an activity that involves bodily movement and has social aspects. First, it is a matter of learning and performing bodily knowledge. To play a music instrument requires skill. Like in dance, a lot of implicit bodily knowledge is involved. For example, Leman (2007) has argued that music engages people 'in a corporal way rather than a cerebral way' (18). And like dance, music is a matter of bodily movement and gestures. Second, music is a social activity. It is aimed at an audience, it is often done together with others (comusicians), and like dance and theatre it takes place in a wider social and cultural con-performance. For example, jazz improvisation is not only a matter of skill and bodily knowledge and gestures; it is also a social activity in which musicians respond to each other and in which there is always a link to the tradition. As Fesmire, who uses the metaphor of music for talking about Deweyan ethics, puts it: 'one does not experiment in a vaccum' (Fesmire 2003, 96). And in classical music, there is less improvisation, but a score and often a conductor (compare with choreographer and director), which in turn also stand within a particular tradition.

As I started to argue in the previous sections, our dealings with technology also involve these elements. Use of technology involves bodily movement and is deeply social in several ways. It also refers to traditions of use; my individual use is always also social in the sense that there are already patterns of use given in my culture, in what we could call a 'form of life' - to use a phrase from Wittgenstein. And it is often the case that my technoperformance responds to the technoperformance of others. Think of not only multiplayer gaming, but also the use of smartphones: I communicate with others, thus constituting a co-performance. There are many people and things involved in music making. Godlovitch (1998) speaks of communities and ecologies of performance; the same can be said about technology use and experience, understood as performance. For example, the way I use my smartphone and a chat app links me to many people and things, and taps into patterns that are already there before I start using it: there are styles and ways of behavior that are typical and appropriate for one medium but not for another. Of course, we may improvise; our use of technology may not be entirely based on a score or conducted, we can improvise with technology. We may take distance from what the "composer" intended or invent a new use by performing it.
But even then, we still tap into (use) patterns that are there before us. For example, a person using a pen as a weapon may draw on a pattern of use that is already given for using a knife (as a weapon).

Improvisation also shows again that there is implicit knowledge involved in technology use. As Dreyfus's work on skill acquisition reminds us (Dreyfus and Dreyfus 1986), driving a car, for example, requires the acquisition of implicit knowledge. Once we are an expert in using a particular technology, we no longer have to think about everything we are doing. We have the skill. The technology is then embodied, not only in Ihde's or Verbeek's sense of being a mediator between us and the world, but also in the sense of having become a skill. Such skill can then become the basis for improvisation. Like in contact improvisation in dance (Kimmel et al. 2018), in which the dance emerges from the interactions between the improvisors, in both music and technology use, there can also be emergent use through embodied creativity by an individual or in a group of people. Such music and such use are then not merely or not mainly based on prior planning or explicit coordination, and the creation involved is not just a matter of something "inner" happening but at least also always emerges in relation to environmental elements (Wheeler 2018), including (other) technologies. In this sense, technology use is always environmental and ecological. For example, invention of new technologies or creative dealing with an engineering emergency does not happen as the mere result of someone's "genius" or inner thought processes; it requires interaction with many things and many people in the environment. This is not very romantic but more accurate. And when and insofar technology use is improvised and emergent, the use is shaped in the performance itself and not beforehand. Improvisation may be necessary when there is no "score" or when the "score" is not sufficient to deal with a problem at hand.

That does not mean, however, that in such cases, technology use is always and totally mindless. In the phase of instruction and learning of skill to use a music instrument or a technology that is new to me, I need to think about what I am doing (see again Dreyfus), and like in music improvisation at all times higher level sense-making may come in, as we can learn from cognitive science. It has been argued that instead of becoming mindless, the music improvisor gains new worlds in and on which to improvise (Torrance and Schumann 2018). Technology, understood as use and technoperformance, also opens up new worlds for action, knowledge, and improvisation. Consider, for instance, the internet and digital gaming. Technology use can also become an expression of what we are and what goals we have, not only as individuals but also as a group of people. Using the music metaphor again, consider the phenomenon of "Woodstock" or rock music: music became the expression of the values and aspirations of an entire counterculture and generation. 
Similarly, technology use can embody and express cultural values (as Ihde, who talks about culture and technoculture in his work, would acknowledge). Consider the car, which considered in use is not only itself a technoperformance involving bodily movement and response to a social situation (traffic), but is also connected to a particular culture. However, which culture exactly is not obvious; also here implicit knowledge and emergence play an important role. For example, it might be that the use of cars is connected with a culture that highly values individual freedom, but this is not something we think about when we use a car, and it is difficult to make the link between the technoperformance and the values explicit. Similarly, usually (that is, in use) we are not aware of the cultural values connected with what we do with our phones or computer, and their connection with wider culture is not immediately clear.

But the metaphor of music also serves us to highlight the temporal dimension of technology use and experience. Music takes place in time and has rhythm and speed. Like dance, it has a specific temporal structure. Dance is movement but so is music. Both have particular temporal characteristics such as rhythm. When we use technology (or one should say: other technology, since music also uses instruments), our use and experience also has such temporal characteristics. Use of technologies always takes place in time. "Technologies in time" can be interpreted as technology being embedded in so-called "objective" or "scientific" linear and quantitative time, or technology can be seen as part of human experience-part of "lived time" - and part of the lifeworld (think, for example, about Bergson's concept of time as durée), or both. Perhaps the latter cannot be articulated completely and has to remain at least in part implicit knowledge. For example, it can be measured how long someone uses a smartphone; but that person's experience of (time while) using the phone may not be entirely open to articulation, and cannot be measured. Furthermore, this time in which technology use is embedded is not unstructured. It has specific characteristics. Use and experience of technology has rhythm and speed, for example. For example, we can analyze the different rhythms of different social media apps and platforms, in a quantitative way or a qualitative way (how does the rhythm feel like?). At a macro-level we can also discuss the rhythm of our society and culture, for example, as shaped by digital technologies, and how this influences the rhythm of human lives and particular personal and social technoperformances.

My suggestion here that technology shapes temporalitye.g.,shapes my experience of time during use of a phone and shapes the rhythm of a culture-presupposes the idea that technology is more than a mere instrument, but influences what we say and do, and how we say and do it. Using McLuhan's metaphor, the medium becomes the message. Using a performance metaphor, technology becomes co-performer and, sometimes, choreographer, director, and conductor of our performances. Let me unpack the latter idea.

\section{Technology as choreographer, director, and conductor of our performances and our lives}

Technology is an instrument, it is something we use. But as philosophers of technology know since at least Heidegger, it is also much more than that. Technology is not just a tool but organizes and controls us. Some people think that this is especially true for digital technologies and intelligent machines; there is a fear that such technologies control us rather than the other way around. Technology also seems to pre-structure our activities and experience, for example, when we behave a certain way during an event with a view to create posts on Facebook. Using the performance metaphors proposed here, these non-instrumental roles of technology can now be expressed not so much by calling technology an "actant" (or co-dancer, co-musician) which "does" things, but more adequately by saying the technology is a choreographer, a director, and a conductor of our lives. These metaphors adequately describe the structuring and pre-structuring (quasi-transcendental) role of technology and can also express the controlling and mastering role of technology.

First, technology organizes our movements. It is a choreographer in the sense that it constrains and shapes our bodily movements when using technology, creates our dances with technology, or directs our movements when and while we use technology. Think of the movements of our fingers when we operate a smartphone: these movements are choreographed by the designer of the operating program and once used, the technology shapes how I (can and should) move. And how we move our fingers on the keyboard of a phone or a computer depends on the design of the keyboard. Our movements are thus pre-structured by others, via the technology. Moreover, in line with contemporary philosophy's insistence on the more-than-instrumental role of technology, we can also make a stronger claim using metaphors from dance and music: technology can not only shape how we move given the constraints of the technology (how we move our fingers on the keyboard of a computer depends on the design of the material keyboard, how we touch a smartphone depends on the software code) but also influence the choreography in the sense of the "composition" of what we "dance" and "play". In the history of music, new instruments have always led to the creation of new music. Consider for instance how the electric guitar which has helped to shape a new kind of music (rock music) or how the computer has shaped a new kind of music (electronic music). Similarly, (other) technologies such as social media 
are not just new media but also tend to shape the message. This stronger claim about media that shape the message is known at least since McLuhan, and of course there is a lot of discussion about what the precise influence of, for example, social media is on what way say and do. For example, do social media encourage hate speech? Do they stimulate fake news? Do they lead to eroded forms of sociality? Do they threaten democracy? For any of such claims, specific arguments should be provided. Moreover, it may be more precise to say that technologies are co-choreographers and co-creators of our technoperformances since users retain some agency, power, and control (see also Sect. 4). But in any case, the metaphors of dance (choreography) and music (composition) help us to reformulate the general stronger claim and provide a framework for further analysis.

My thesis is then that technology is a choreographer understood as a co-creator of our dances, co-creator of our technoperformances, in at least two senses: the (weaker and more literal) sense of shaping and constraining our bodily movements (as in: if I want to type the word "piano" on this computer, then I have to move my hands such and such), and the (stronger and more metaphorical) sense of shaping and influencing what we do and say (influencing which words I type). Using choreography as a metaphor, then, enables us to say that technology does not only choreograph my bodily movements; it also choreographs what I do and how I live. It organizes the dances of my actions, my thinking, and my life.

Note that the choreography or composition is not always (completely) given before use/performance. Technology can also choreograph in the sense of directing our movements during use. This is especially the case when smart technologies shape what we do in real time. Consider a running app which directs our movements by means of measurements and advice during use. Here usually the way my legs and feet move is not pre-choreographed by the app (although here too technology can intervene, for example, a video of how I put my feet down can teach me something about how I move and encourage me to run differently) but such apps or combinations of apps may direct my movements in the sense of advising when I should run (shaping my running routine), how long I should run, how fast I should run, which trajectory I should follow, and so on. Some of this influence happens during use. And perhaps in the end, through regular use and the related creation of habits, the app shapes how I lead my life. But this may not be known on beforehand and not determined on beforehand by the technology (nor indeed by the user). It happens in the process of use. The metaphors of improvisation and emergence during performance then enable us to make the following claim about technology: not only how I move with technology (at a given time) but also the dance as a whole (what I do with technology) may emerge during our technoperformances. The dance or the work of music may not be clear yet from the beginning, but by improvising with the technology I arrive at a performance, a performance emerges: a technoperformance (and with the technoperformance, new knowledge and new technoperformative worlds emerge).

Note also that in performance, understood as improvisation and as involving skilled, embodied knowledge, the "how" and "what" are not so clearly distinguished. If how I move changes, then the performance as a whole (the "what", the "work") also changes. There is no "work" independent of the performance. And this is also true, to some extent at least, for dance, theatre, and music that is pre-choreographed, pre-scripted, and pre-composed: what the dance, music, or theatre "is ", is what it becomes during the performance, which can never be reduced to its script. Similarly, technology use is never the mere execution of whatever the user or designer had in mind. If we apply that metaphor to technology: the technology "is", is what it becomes in and through use. For example, what a specific digital social medium "is" cannot be defined in technical terms alone; instead of "is"-type of philosophical questions, we need a phenomenology of its uses/performances to better understand the medium.

Whether technology merely influences and constrains our micro-movements (say how I move my fingers on the screen of my smartphone) or also influences the dance of our lives, usually we are not aware that technology choreographs us. Tuuri et al. write that smart technologies "affect our bodily flow of everyday activities and movements - that is, routines and everyday choreographies we regularly engage in, but whose real contents and embedded meanings we rarely trouble ourselves to become aware" (Tuuri, Parviainen, and Pirhonen 2017, 495). Consider the gestures we perform when using a smartphone and checking for messages, which has become part of our kinetic daily routines. Once we learned the gestures and acquire the skill, we no longer think about the movements we make with our arms, hands, and fingers, or about our posture when we hold the phone while standing or sitting. Furthermore, usually we are also not aware of the influence technologies have on what we do and how we lead our lives. Here philosophy of technology can have a therapeutic role: it can reveal to us how technology moves us, literally and metaphorically, and perhaps also intervene. The philosopher then acts as a kind of physiotherapist or kinesitherapist. She can show how we move technology and how technology moves us, and perhaps also how we can change these movements, how we can move in a better way (see also Sect. 4 for the ethical and political questions).

Second, technology shapes our social lives, including our social roles and identities. As we perform our identities and roles, technology is not a mere tool but may take on the role of director. Consider again social media: how I present 
myself to others is not something that is fixed on beforehand, but is shaped and pre-structured by my use of the relevant platform, which influences how I present myself (consider for instance the tendency to present a better version of oneself but also the various styles of presenting and performing oneself, e.g.,by means of selfies, a particular style of writing, etc.). When I use social media, my performance on and through these media is thus not fully scripted and directed by me; I am not fully in control of how I present myself to others. As suggested earlier, the technology may even shape my "offline" performances, that is, performances on different stages. I may act with-a-view-to-present-myself-onFacebook. The technology (and at the same time the culture) thus scripts and directs me. Social media technologies, next to human others that are part of my social life (online and offline), co-write my script and direct me. Social media and role-playing games are not only "media" that may influence our perception (of the world, of others, of technology); they also organize and direct our performances on the various stages of the social life. Script becomes prescription. Direction is normative. (I will return to this point.)

In response to Latour and Verbeek, we can now say that we have a more complete toolkit of theatre metaphors to fine-tune what happens when we use technology. Technology not only be co-actor (actant) but also director, and this helps to make sense of how technology structures and shapes our performances. Consider the by-now well-known example of the speed bump. For Latour and Verbeek, the speed bump is a thing that becomes an actant when it slows down the cars. But this makes it seem as if there are no other humans involved in doing that, and defines the relation between human and speed bump in a symmetrical and non-hierarchical way, as if both could have an equally strong influence on each other (they are supposed to be co-actors) and as if humans are not involved in what things do. By contrast, one could also describe what happens using the director metaphor: based on the script of traffic rules for that area (written by humans), the speed bump, together with the humans that decided that in that area there is a speed restriction in place, act as co-directors of the drivers as human actors (which, in turn, use cars that can be seen as co-actants that have opposite effects). If the speedbump really was a "co-actor" or actant, the human driver could perhaps negotiate; in any case, there would be a dynamic between the actor and actant. The director metaphor leaves less room for negotiation and expresses that the speedbump shapes the behavior without much influence or power on the part of the human driver. One can also describe different performative spaces in which decisions are made that prestructure the entire situation before the "act" or "direction" of the speed bump takes place. Human performances create rules and create the speedbump (which has to be built). There is a history of performances. Using the direction metaphor to describe what the speed bump is and "does" seems to make more sense to me, and more generally a discussion of the metaphors involved leads potentially to a more sophisticated description. This is achieved by fully harvesting the metaphor and by moving beyond talk about mediations taking place between (individual) humans and things, which then artificially have to be given a social "con-text". Instead, we can say now that there are performances and con-performances-by humans-which are co-directed by things. A fully developed performative framework already has the social dimension built-in. And using the directing metaphor, next to the scripting metaphor already used by Latour, also enables us to talk about the normativity of technological artifacts in a more refined way, including the structural elements such as the spaces within which use and experience of technology takes place. I have also added the time dimension; this takes us to the aspect of temporality and in particular how temporality is shaped by technology.

Third, technology organizes the temporal dimension of our lives. Technology not only merely take place in timeas use and performance it is part of a history of uses and performances-but also shapes and configures that time. It organizes the temporal structure of our actions and our lives, and contributes to giving our activities and experiences their rhythm and speed. For example, social media are not mere tools but shape what we do during the day and when (e.g.,getting up and checking your smartphone and social media for messages) and may give us the feeling that our personal lives are more hurried and busy. In this sense, technologies are conductors of our lives: they organize and control the music of our lives, including rhythm and tempo. A (post)phenomenology of technology use and experience should take into account this temporal dimension. Human-technology relations do not only take place in time and have a history; they also configure time and constitute a particular kind of organization and structuring of time: "objective", measured time (consider the industrial machine that controls the time of the workers, social media that create a rhythm of checking our phones, or the digital calendar that controls what we do when in our day-see for example Wajcman 2019) and "subjective", felt time (e.g.,clocks giving us the feeling that we need to hurry and have too little time or a meditation app that tries to create a different timeexperience-consciousness). In such technoperformances, technologies are not only tools but also conductors, intervening in the temporal structure of our performances, lives, and existence.

Note, finally, that we can also ask in what sense technologies themselves can "perform" and can be "performers". So far it has been assumed that there are only human performers. Could there be nonhuman performers? Could there be hybrid performers? I will not fully discuss this question here, but it seems that for technologies—say machines-to 
count as performers, (pre)conditions need to be fulfilled that have to do with all the elements discussed in this paper. These include lived embodiment as a condition for a moving body that is also experienced, lived sociality as a condition for social performance, ability to improvise, and lived time/temporality. It is highly doubtful, if not impossible, that machines could meet these conditions. However, some machines can sometimes under certain conditions be perceived as performing in the senses outlined here (they can be perceived as having a moving body and lived embodiment, sociality, improvisation abilities, experience of temporality, etc.- designers can try to create this illusion), and perhaps human-machine hybrids could meet the conditions.

\section{Implications for ethics and politics of technology: some normative questions}

I already suggested that technology can have normative effects. Using the metaphors of dance, theatre, and music, including the metaphor of improvisation (versus pre-scripted performance), we can not only describe the phenomenology and hermeneutics of technology use, but also ask ethical and political questions directed at issues of normativity and power.

First, who choreographs us and who should choreograph us, as persons and as societies? Who or what moves us? Who should be in control of which movements? How can we better organize movements of people and things? This metaphor can not only be used in an abstract way, but it can also make us aware of the importance of movement (literally understood). The ethical and political question includes a normative kinetic question, and ethics of technology should take this into account. Moving and dancing with technology is an ethical and political matter. It is not only the case that bodies and movement can literally be used for political purposes such as demonstrations and other political performances and interventions - for example, Parviainen (2010) has helpfully analyzed 'choreographies of resistance' (311) — but rather that movements in general are not necessarily ethically and politically neutral, and that, therefore, an ethics of technology should include inquiries into what one could call normative kinetics. Consider, for example, Young's paper "Throwing Like a Girl" (Young 1980) which reveals how movements can be gendered. How we move with technology and how technology moves us can and should also become an ethical and political issue. For example, an analysis such as Rosenberger's could be developed into an analysis of how particular artifacts mediate and pre-structure the movements of people in public spaces. And are, for instance, movements with smartphones gendered? Furthermore, going beyond literal uses of the vocabulary from dance and using the metaphor of improvisation, we can ask how much room we have to choreograph our lives and our societies. To what extent can users improvise, given that many movements related to electronic devices seem to be fixed on beforehand? How much room do the choreographers of our technologies-and hence the choreographers of our lives-leave for improvisation? How much room should they leave us?

Second, who and what directs and should direct the social life with technology? Who builds and configures the stages on which we present ourselves to others and on which we constitute our identities as we perform? What power do users of these media have, that is, what power do individual performers have to change their performances? Can they improvise? Are there ways to resist the power of those who create these performative spaces? Can we change the performative spaces? What is the normative influence of these technologies on other performative stages of our daily lives? To what extent do I direct my own life, and to what extent are others and the technologies I use co-directors of my life? What acts, roles, and identities do specific technologies encourage? What conversations does it tend to promote or exclude? Is there still a "backstage" where we can rest from our frontstage performances, or do current social media organize our performative spaces in such a way that this is no longer possible, as they seem to be colonizing what used to be called the "private" sphere, including our homes and bedrooms? Are we now always frontstage, and is this good for us? And what kind of form of life is constituted by these different performances and performative spaces?

Third, who or what configures and should configure the temporal horizon and structure of our lives? Who or what should decide how we organize our day? Are we becoming the servants of our digital calendars, as Wajcman's (2019) research suggests? Should we let technology decide the tempo of our lives? Is life speeding up? For which audiences are we actually performing? Should we let the designers of digital technologies shape our lives in this way? How can we resist or intervene? What are alternative ways of organizing the temporal structure of our activities and lives? How can we live and experience differently? What different technologies do we need for this? Is it time for different time technologies? And how much time and space do we still have to improvise and play in our lives and with technology, even if such improvisations will always rely on patterns of use and patterns of life that are already there before us? To what extent do we play (with) technologies or they play (with) us? Should we let them play (with) us?

Whatever the answer to these descriptive and normative questions may be, they probably do not constitute an either/ or issue. It is plausible that we will always have some control over our lives and that technology does not completely choreograph, direct, or conduct us. This is why the metaphors of co-choreographer, co-director, and co-conductor, next to the metaphor of improvisation, are probably more 
adequate to ask these normative questions. If we still have some agency, power, and control-as individuals and as societies, then humans and the technologies they use are cochoreographers, co-directors, and co-conductors. And as coperformers, humans have some room to improvise. But we should also ask the normative question: the question to what extent and how precisely technology should co-choreograph, co-direct, and co-conduct us - and indeed how and to what extent we (human users and human societies) can and should co-choreograph, co-direct, and co-conduct our lives and our living together. This question remains pertinent and urgent, especially if and as we seem to become more dependent on digital technologies today.

\section{Conclusion}

To conclude, using performance metaphors we can start to develop a richer and more comprehensive phenomenology and hermeneutics of technology use, which can help postphenomenology and posthermeneutics to expand its theory from a limited conceptual framework of human-technology relations focused on artifacts and their mediations of individual perception (Ihde) and acting by artifacts (Latour and Verbeek) to a conceptual framework for understanding technology use and experience that takes seriously the moving, social, and temporal dimensions of technology use and experience-indeed the kinetic, social, and temporal dimensions of being human. This performance-oriented approach, which through its metaphors shifts more attention to the human user, may also be helpful to theory beyond (post)phenomenology and even beyond philosophy of technology: it promises a new conceptual framework for thinking about the relations between humans and technology that may also of interest to fields such as philosophical anthropology, science and technology studies, innovation studies, human-computer interaction studies, and systems theory. Moreover, it enables not only better and more comprehensive descriptions of the phenomenology and hermeneutics of technology use but also opens up interesting normative questions, suggesting that there is something like an ethics and politics of technoperformances. This seems especially important with regard to smart technologies such as social media, which increasingly co-choreograph, co-direct, and co-conduct (what we do in) our lives. As such, proposed approach does not exclude analysis of specific technologies as material artifacts; it only asks to embed this analysis in, and relate it to, a larger conceptual space in which there is more attention to human beings as performative beings: beings that perform with technology and are partly choreographed, directed, and conducted by technology. Beings that, rather tragically perhaps, are never fully in control of their own technoperformances as they are directed by the smart technologies they themselves invented and improvise their way through life.

Acknowledgements Open access funding provided by University of Vienna.

Open Access This article is licensed under a Creative Commons Attribution 4.0 International License, which permits use, sharing, adaptation, distribution and reproduction in any medium or format, as long as you give appropriate credit to the original author(s) and the source, provide a link to the Creative Commons licence, and indicate if changes were made. The images or other third party material in this article are included in the article's Creative Commons licence, unless indicated otherwise in a credit line to the material. If material is not included in the article's Creative Commons licence and your intended use is not permitted by statutory regulation or exceeds the permitted use, you will need to obtain permission directly from the copyright holder. To view a copy of this licence, visit http://creativecommons.org/licenses/by/4.0/.

\section{References}

Akrich M, Latour B (1992) A summary of a convenient vocabulary for the semiotics of human and nonhuman assemblies. In: Bijker W, Law J (eds) Shaping technology/building society: Studies in sociotechnical change. The MIT Press, Cambridge, pp 259-264

Butler J (1988) Performative acts and gender constitution. Theatre J 40:519-531

Dreyfus HL, Dreyfus SE (1986) Mind over machine: the power of human intuition and expertise in the era of the computer. Blackwell, Oxford

Fesmire S (2003) John Dewey and moral imagination. Indiana University Press, Bloomington

Foster SL (2011) Choreographing empathy. Routledge, London

Godlovitch S (1998) Musical performance. Routledge, London

Goffman E (1956) The presentation of self in everyday life. Social Sciences Research Centre, Edinburgh

Ihde D (1990) Technology and the lifeworld. Indiana University Press, Bloomington

Ihde D (1993) Postphenomenology. Northwestern University Press, Evanston

Ihde D (1999) Expanding hermeneutics. Northwestern University Press, Evanston

Ihde D (2002) Bodies in technology. University of Minnesota Press, Minneaopolis

Kimmel M, Hristova D, Kussmaul K (2018) Sources of embodied creativity: interactivity and ideation in contact improvisation. Behav Sci 8:1-37

Klemola T (1991) Dance and embodiment. Ballett Int 14:71-80

Kozel S (2007) Closer. The MIT Press, Cambridge

Latour B (1993) We have never been modern. Translated by Catherine Porter. Harvard University Press, Cambridge

Leman M (2007) Embodied music cognition and mediation technology. The MIT Press, Cambridge

Merleau-Ponty M (2005) Phenomenology of perception, Smith C (trans). Routledge, New York

Parviainen J (2010) Choreographing resistances. Mobilities 5:311-329

Pickering A (1995) The mangle of practice: time, agency, and science. University of Chicago Press, Chicago

Rosenberger R (2017) Callous objects: designs against the homeless. University of Minnesota Press, Minneapolis

Schechner R (1988) Performance theory. Routledge, New York

Sheets-Johnstone M (2015) The phenomenology of dance. Temple University Press, Philadelphia 
Torrance S, Schumann F (2018) The spur of the moment: what jazz improvisation tells cognitive science. AI Soc 34:251-268

Tuuri K, Parviainen J, Pirhonen A (2017) Who controls who? Embodied control within human-technology choreographies, Interact with Comput 29:494-511

Van Den Eede Y (2005) Tracing the tracker: A postphenomenological inquiry into self-tracking technologies. In: Roserberger R, Verbeek P-P (eds) Postphenomenological investigations: essays on human-technology relations. Lexington Books, Lanham, pp $143-158$

Verbeek PP (2005) What things do. Pennsylvania State University Press, University Park

Wajcman J (2019) The digital architecture of time management. Sci Technol Hum Values 44:315-337
Wellner G (2016) A postphenomenological inquiry of cell phones: Genealogies, meaning, and becoming. Lexington Books, Lanham

Wheeler M (2018) Talking about more than heads: the embodied, embedded and extended creative mind. In: Gaut B, Kieran M (eds) Creativity and philosophy. Routledge, Abingdon and New York, pp 230-250

Young IM (1980) Throwing like a girl. Hum Stud 3:137-156

Publisher's Note Springer Nature remains neutral with regard to jurisdictional claims in published maps and institutional affiliations. 